\title{
COMPARATIVE STUDY BETWEEN CALCIUM CHANNEL BLOCKER AND PROGESTERONE THERAPY IN PREVENTION OF RECURRENT PRETERM LABOR
}

\author{
By \\ Raffat M. Hassan, Farid I. Hasan and Mofeed F. Mohammed \\ Department of Obstetrics and Gynecology, Faculty of Medicine, Al-Azhar University \\ E-mail: raffat_net@hotmail.com
}

\begin{abstract}
Background: Preterm labor (PTL) is the leading cause of perinatal and neonatal morbidity and mortality and strongly related to the developmental and neurological disabilities later in life.

Objective: To compare between calcium channel blocker and progesterone in the prevention of Preterm Labor in patients with history of recurrent spontaneous preterm labor.

Patients and Methods: A comparative clinical study was done at Al-Hussein Hospital on one hundred pregnant women with history of previous spontaneous preterm labors were selected in this study, and randomly arranged into two groups: calcium channel blocker group (A), and progesterone group (B).

Results: There was no statistically significant difference between all groups as regards age, parity and number of previous preterm labors, There was a statistically significant difference between the progesterone group and the calcium group as regards GA at delivery, with higher percentage of lower GA at delivery among the progesterone group (35.61 weeks) compared to the calcium group (37.11 weeks), There was a statistically significant difference between the progesterone group and the calcium group as regards mean values of birth weight with higher percentage of lower birth weight among the progesterone group $(2.37 \mathrm{~kg})$ compared to the calcium group $(2.93 \mathrm{~kg})$, There was a statistically significant difference between the progesterone group and the calcium group as regards mean values of five minutes APGAR Score with higher percentage of lower five minutes APGAR Score among the progesterone group (7.66) compared to the calcium group (8.57), There was no statistically significant difference between all groups as regards the mode of delivery. There was a statistically significant difference between the progesterone group and the calcium group as regards NICU admission with higher percentage of NICU admission among the progesterone group (40\%) compared to the calcium group (17.1\%), There was a statistically significant difference in different studied groups before and after progesterone administration as regards mean values of serum progesterone, There was a statistically significant difference in different studied groups before and after progesterone administration as regards mean values of serum calcium.
\end{abstract}

Conclusion: The use of calcium channel blocker and progesterone reduced the rate of preterm labor, prolonged gestational age at delivery, reduced the frequency of uterine contractions, and improved the symptoms of preterm labor in women with history of recurrent spontaneous preterm labors. Calcium channel blocker was more superior on progesterone as regards prevention of recurrent preterm labor.

Key words: Preterm labor - progesterone - calcium channel blocker. 


\section{INTRODUCTION}

Preterm labor is defined as the presence of uterine contractions of sufficient frequency and intensity to effect progressive effacement and dilation of the cervix prior to term gestation (before completing 37wks of gestation) (ACOGpractice bulletin no. 127, 2012).

The incidence of this problem is rising and is reported to be $15 \%$ of pregnancies in the developed world. So, its prevention is considered a major challenge for obstetricians (Chen et al., 2019).

By gestational age, $5 \%$ of preterm labors occur at less than 28weeks (extreme prematurity), $15 \%$ at $28-31$ weeks (severe prematurity), $20 \%$ at $32-33$ weeks (moderate prematurity), and 6070\% at 34-36 weeks (near term) (Lipi et al., 2013).

Survival of the preterm infant is directly related to gestational age at delivery. Survival increases from less than $50 \%$ before 24 weeks to more than $95 \%$ by 33 weeks' gestation and there is a corresponding inverse relationship between the risk of severe disability in survivors and gestational age at delivery (Chenet al., 2019).

Complications from preterm birth are not limited to the neonatal period such as in retinopathy of prematurity, intraventricular hemorrhage, necrotizing enters colitis, respiratory disorders and sepsis. They can also constitute sequelae such as abnormal neurophysiological development in early childhood and underachievement at school (Nayeri et al., 2018).

The early detection of pregnant women at high risk for preterm labor could be the best way to prevent preterm labor (Urquhart et al., 2017).

Most common interventions recommended to prevent preterm birth have been proved to have a little or no benefit. However, bed rest, once universally advocated, is now largely historical. Cerclage, antibiotics or tocolytics may be beneficial only in specific circumstances (Lucovnik et al., 2011).

Calcium channel blockers exert their tocolytic effect by preventing the influx of extracellular calcium ions into the myometrial cell. They are entirely nonspecific for uterine as distinct from other smooth muscle cells, but have been demonstrated in vitro to have a potent relaxant effect on human myometrium (Gáspár et al., 2013). The most widely used and studied CCB is nifedipine, which along with nifedipine, belongs to the dihydropiridine group. Nifedipine was first reported in an observational study in 1980 to be an effective tocolytic agent with minimal side effects. Nifedipine can be given orally or by intravenous route, whereas nifedipine can only be administered orally (Conde-Agudelo et al., 2011).

Progesterone is useful in allowing pregnancy to reach its physiologic term. In animal studies, medroxyprogesterone treatment prevented labor and possessed anti-inflammatory activity in vivo. Moreover, progesterone antagonists given at term increase the rate of spontaneous labor (Norwitz et al., 2011).

Progesterone and $17 \alpha-$ hydroxyprogesterone acetate slow the process of cervical ripening, and this is the rationale for prophylactic long-term 
progestin supplementation mostly studied so far. However, progesterone (but not $17 \alpha$-hydroxyprogesterone acetate) also inhibits myometrial activity even after the cervix has already ripened. Moreover, these effects depend greatly on the vehicle used and the route of administration. Understanding different mechanisms of action, as well as the importance of progestin formulation, vehicle and route of administration is the key to finding the optimal progestin treatment for prevention of preterm birth (Lucovnik et al., 2011).

Progesterone administration was considered to be effective in the prevention of PTL in women at risk, especially women with history of previous spontaneous PTL (Doddetal., 2010).

The aim of this study was to compare between calcium channel blocker and progesterone in the prevention of preterm labor in patients with history of recurrent spontaneous preterm labor.

\section{PATIENTS AND METHODS}

This comparative clinical study was carried out at Al-Hussein Hospital. One hundred pregnant women who have history of previous spontaneous preterm labors, singleton pregnancy, gestational Age of 20 to 24 weeks or past history of one or more spontaneous preterm labor. They were randomly arranged into two groups calcium channel blocker group (A) and progesterone group (B).

\section{Exclusion criteria:}

Patients with multi-fetal pregnancy, history of ante partum PROM, cervical incompetence or current cervical cerclage, known fetal anomaly, hypertension requiring medications, progesterone or heparin treatment in current pregnancy or history of thrombo-embolic disorders, known allergy toprogesterone, known liver disease or established preterm labor.

\section{All women were subjected to:}

\section{A. At the first antenatal visit:}

Full History taking, were full personal, obstetric, menstrual and medical history was taken. Data were collected in a special form for each patient. Complete General and abdominal examination and Routine laboratory investigations (full labs). Estimation of gestational age; estimation was done based on the last menstrual period and ultrasonography up to12 weeks or by two concordant scans between 12 and 24 weeks. Routine transabdominal ultrasound to assess the gestational age and to exclude fetal anomalies. Trans-vaginal ultrasound every four weeks to assess cervical length and funneling, prophylactic medical treatment.

All pregnant women in the study received prophylactic medical treatment for bacterial vaginosis and Chlamydial infection in the form of Azithromycin tablets $(500 \mathrm{mg}$ ) orally once daily for 3 days, and Metronidazole tablets $(250 \mathrm{mg}$ ) three times per day for 7 days. Medications were given just before starting progesterone therapy.

Treatment was started at 20-24 weeks gestation; (Group A) were given calcium channel blocker tablets twice daily, and (Group B) were given progesterone. Treatment was continued until completed 36 weeks gestation or until occurrence of PROM or delivery.

All women were advised about the benefit of the drug used and a written approval of the study was taken from each 
woman. A schedule of next visits was given to each woman.

\section{B. At the follow up visits:}

All pregnant women were submitted to uterine contraction monitoring by an external tocodynamometer every other week for 60 minutes by an external monitor from 28 to 36 weeks of gestation while women in left lateral position. We determined the frequency of contractions. A positive test was considered when there were four or more contractions per hour before the 30thweek of gestation, and from 30 weeks onward, 6 or more contractions per hour. All pregnant women were asked for symptoms of preterm labor like heaviness, cramps, abdominal colic, and sudden gush of fluid.

\section{Statistical analysis:}

Recorded data were analyzed using the statistical package for the social sciences, version 20.0 (SPSS Inc., Chicago, Illinois, USA). Quantitative data were expressed as mean \pm standard deviation (SD). Qualitative data were expressed as frequency and percentage. Probability Pvalue $<0.05$ was considered significant. $t-$ test was used to compare means and Chisquare test was used to compare frequencies.

\section{RESULTS}

There was no statistically significant difference between all groups as regards the age, parity and number of previous preterm labors. There was a statistically significant as regards GA. at delivery with higher percentage of Lower GA at delivery among the progesterone group (35.61 weeks) compared to the calcium group (37.11 weeks). There was a statistically significant difference as regards mean values of birth weight with higher percentage of lower birth weight among the progesterone group $(2.37 \mathrm{~kg})$ compared to the calcium group $(2.93 \mathrm{~kg})$. There was a statistically significant difference between mean values of five minutes APGAR Score with higher percentage of lower five minutes APGAR
Score among the progesterone group (7.66) compared to the calcium group (8.57). There was no statistically significant difference as regards the mode of delivery. There was statistically significant as regards NICU admission with higher percentage of NICU admission among the progesterone group (40\%) compared to the calcium group $(17.1 \%)$.

There was a statistically significant difference before and after progesterone administration as regard mean values of serum progesterone. There was a statistically significant difference before and after progesterone administration as regards mean values of serum calcium. 
Table (1): Comparison between groups

\begin{tabular}{|l|c|c|c|}
\hline Parameter $\quad$ Group & $\begin{array}{c}\text { Progesterone group } \\
(\mathbf{n = 5 0 )}\end{array}$ & $\begin{array}{c}\text { Calcium group } \\
(\mathbf{n = 5 0 )}\end{array}$ & p-value \\
\hline Age (yrs.) & $28.65 \pm 4.82$ & $29.14 \pm 4.15$ & $>0.05$ \\
\hline Parity & $2.95 \pm 0.57$ & $3.19 \pm 0.61$ & 0.045 \\
\hline No. of PLT & $2.55 \pm 0.52$ & $2.53 \pm 0.52$ & $>0.05$ \\
\hline Gestational age & $35.61 \pm 1.12$ & $37.11 \pm 1.26$ & $<0.001$ \\
\hline Birth weight (kg) & $2.37 \pm 0.37$ & $2.93 \pm 0.30$ & $<0.001^{* *}$ \\
\hline Apgar score & $7.66 \pm 0.75$ & $8.57 \pm 1.14$ & $0.001^{*}$ \\
\hline Delivery by CS & $16(32 \%)$ & $19(38 \%)$ & $<0.05$ \\
\hline Vaginal delivery & $34(68 \%)$ & $31(62 \%)$ & $<0.05$ \\
\hline Not needing NICU & $30(60.0 \%)$ & $41(82 \%)$ & $<0.05$ \\
\hline Needing NICU & $20(40.0 \%)$ & $9(18 \%)$ & $0.02^{*}$ \\
\hline Serum progesterone before & $50.88 \pm 1.70$ & $51.50 \pm 1.97$ & $>0.05$ \\
\hline Serum progesterone after & $95.70 \pm 1.57$ & $103.00 \pm 2.02$ & $<0.001^{*}$ \\
\hline Serum calcium (mg/dl) before & $13.74 \pm 0.32$ & $13.91 \pm 0.37$ & $<0.02^{*}$ \\
\hline Serum calcium (mg/dl) after & $11.26 \pm 0.30$ & $9.87 \pm 0.38$ & $<0.001^{*}$ \\
\hline
\end{tabular}

\section{DISCUSSION}

Prematurity is the leading cause of neonatal death and handicap, Improvement in neonatal care have led to higher rates of survival among very preterm infants, but a major effect on the associated mortality and morbidity will be achieved only by better identification of women at higher risk for preterm labor and by development of an effective intervention to prevent this complication (Cupen et al., 2017).

Progesterone is a steroid hormone that helps to maintain pregnancy. Removal of progesterone, or blockage of its receptors, reliably ends pregnancy at all gestational ages, and in many non-human species, falling levels precipitate natural labor (Lucovnik et al., 2011).

The vasodilator effect of progesterone on uterine circulation in the non-pregnant female and during the first trimester of pregnancy is well known, but little information is available about its effect on uterine and fetal circulations later in gestation. In one study performed by
Barda et al. it showed that vaginal micronized progesterone used for the prevention of PTL was associated with a significant reduction in the fetal middle cerebral artery (MCA) pulsatility index (PI) but with no effect on uterine circulation (Vafaei et al., 2016).

Calcium channel blockers are used to control hypertension, but it had been found to have a role in decreasing uterine premature contractions. There have been reports of the lack of action of nifedipine in premature contractions. Uterine contractile activity is regulated by the increase in intracellular $\mathrm{Ca} 2+$ concentration in the myometrial cells (Gáspár et al., 2013).

The current study included 100 pregnant women selected on basis of previous one or more preterm labor, singleton pregnancy and pregnancy at gestational age less than 24 weeks and excluded ante-partum ROM, cervical incompetence, cerclage, congenital fetal malformations, hypertension requiring medications, progesterone or heparin 
therapy or history of thrombo-embolic disorders, known liver disease and progesterone allergy.

Gestational age was calculated on the basis of the last menstrual period, and ultra-sonographic examination. Medications started at 24 weeks of gestation and stopped at the end of 36 weeks of gestation and proceeded by prophylactic medical treatment for bacterial vaginosis.

There was no statistically significant difference between the two groups as regarding to age, parity, mode of delivery and number of previous preterm labors.

This agreed with the studies of Fonseca et al., (2014), Meis et al., (2015) and deFonseca et al., (2016).

In a meta-analysis of RCT by Farine et al., (2018), there is a good evidence to recommend the use of vaginal progesterone $200 \mathrm{mg}$ daily in the prevention of PTL in women with short cervix $<15 \mathrm{~mm}$ detected during TVS scanning at 22-26 weeks. In the prevention of recurrent PTL in women with previous PTL, vaginal progesterone $100 \mathrm{mg}$ daily was advised, or IM 17 alpha hydroxyl progesterone $250 \mathrm{mg}$ once weekly. As regards timing of starting progesterone for prevention of PTL, no apparent benefit of early start before 20 weeks and also the use of higher doses is not beneficial (Dodd et al., 2013).

This study compares calcium channel blocker with progesterone for the prevention of PTL, we found that both were effective in the prevention of threatened PTL, PTL < 37 weeks and PTL $<34$ weeks in women at risk with higher efficacy in the calcium channel blocker group running in agreement with many previous studies (Vafaei et al., 2016).

On the other hand, one study by O'Brien et al., (2012) concluded that vaginal progesterone did not reduce the rate of early PTL, neonatal morbidity or mortality and this could be explained by performing their study on women with one risk factor (previous PTL) and considering the primary outcome PTL < 32 weeks, also, they used progesterone in a dose of $90 \mathrm{mg}$ and in the form of vaginal gel.

Some studies found that although calcium channel blocker is effective in the prevention of PTL, it was not effective in reducing the rate of hospital admission for PTL (threatened PTL) (Meis et al., 2016).

In this study and in accordance with previous studies by Tita et al. (2015) and Farine et al. (2018) the mean birth weight and the mean GA at delivery were significantly higher in the calcium channel blocker treated group in comparison with the progesterone treated group.

Also, our results showed that the ratio of neonatal ICU admission to neonatal mortality reduced in both groups that had received calcium channel blocker in relation to the progesterone group.

On the other hand, two other studies reported that the ratio of neonatal admission to ICU was significantly lower in women who had received progesterone but without changes in the neonatal deaths (Cetingoz et al., 2011 and Tita et al., 2015).

The vasodilator effect of progesterone on fetal cerebral circulation may be supported by animal studies that showed that the brain is sensitive to progesterone 
during critical periods of development and maturation and presence of progesterone receptors in the brain, Also progesterone reduces brain edema in animal models ( $X u$ et al., 2014).

As regards serum progesterone level before and after progesterone administration, our study revealed that it was below the normal level at $24 \mathrm{wks}$ measuring approximately 50ng/ml compared to the average normal level at this gestational age $73 \mathrm{ng} / \mathrm{ml}$.

Six weeks after progesterone administration (at thirty weeks gestation), serum progesterone level was approaching the average normal level at this age (100ng/ml).

No data from RCTs and other studies indicate that progesterone use in the prevention of PTL was not safe, apart from a single retrospective study by Rebarber et al., (2014) who showed that the incidence of gestational diabetes mellitus was $12.9 \%$ in women treated by I.M 17 alpha hydroxyl progesterone (250 mg weekly) compared to $4.9 \%$ in control cases. In this study, safety could not be confirmed due to the small number of cases and further large series studies are advocated.

\section{CONCLUSION}

Prophylactic use of progesterone reduces the rate of preterm labor, prolongs gestational age at delivery, reduces the frequency of uterine contractions, and improves the symptoms of preterm labor in women with history of recurrent spontaneous preterm labors.

Calcium channel blockers have superior effect on inhibiting premature uterine contractions in comparison with progesterone administration and prolong gestation ages, lowering preterm births and liability into NICU admissions.

\section{REFERENCES}

1. ACOG practice bulletin no. 127 (2012): Management of preterm labor. Obstet Gynecol., 119(6):1308-1317.

2. Berghella V. (2012): Management of Preterm Labor. Queenan's Management of High-Risk Pregnancy, 24:374-379.

3. Cetingoz E, Cam C, Sakalli M, Karateke A, Celik $\mathrm{C}$ and Sancak A. (2011): Progesterone effects on preterm birth in high-risk pregnancies: a randomized placebo-controlled trial. Arch Gynecol Obstetrics, 283:423-9.

4. Chen KH, Chen IC, Yang YC and Chen KT. (2019): The trends and associated factors of preterm deliveries from 2001 to 2011 in Taiwan. Medicine, 98(13): 1235-1244.

5. Chen KH, Chen IC, Yang YC and Chen KT. (2019): The trends and associated factors of preterm deliveries from 2001 to 2011 in Taiwan. Medicine; 98(13): 1211-1214.

6. Conde-Agudelo A, Romero $\mathbf{R}$ and Kusanovic JP. (2011): Nifedipine in the management of preterm labor: a systematic review and met analysis. American Journal of Obstetrics and Gynecology, 204(2):134-138.

7. Cupen K, Barran A, Singh $V$ and Dialsingh I. (2017): Risk factors associated with preterm neonatal mortality: a case study using data from Mt. Hope Women's Hospital in Trinidad and Tobago. Children, 4(12):108-113.

8. Da Fonseca EB, Bittar RE, Carvalho MH and Zugaib M. (2013): Prophylactic administration of progesterone by vaginal suppository to reduce the incidence of spontaneous 
preterm birth in women at increased risk: a randomized placebo-controlled doubleblind study. American Journal of Obstetrics and Gynecology, 188(2):41924.

9. De Franco, E., O'brien, J., Adair, C., Lewis, D., Hall, D. and Fusey S. (2015): Vaginal progesterone is associated with a decrease in risk for early preterm birth and improved neonatal outcome in women with a short cervix: a secondary analysis from a randomized, doubleblind, placebo-controlled trial. Ultrasound in Obstetrics \& Gynecology, 30(5): 697-705.

10. Dodd JM and Crowther CA. (2010): The role of progesterone in prevention of preterm birth. International Journal of Women's Health, 1:73-77.

11. Dodd JM, Flenady V, Cincotta $R$ and Crowther CA. (2013): Prenatal administration of progesterone for preventing preterm birth. Cochrane Database Syst Rev; CD004947.

12. Farine D, Mundle WR, Dodd J, Basso M, Delisle MF, Grabowska K, Hudon L, Menticoglou SM, MurphyKaulbeck LC, Ouellet A and Pressey T. (2018): The use of progesterone for prevention of preterm birth. Journal of Obstetrics and Gynaecology Canada, 30(1):67-71.

13. Fonseca EB, Celik E, Parra M, Singh $M$ and Nicolaides KH. (2014): Progesterone and the risk of preterm birth among women with a short cervix. New England Journal of Medicine, 357(5):462-9.

14. Gáspár R and Hajagos-Tóth J. (2013): Calcium channel blockers as tocolytics: principles of their actions, adverse effects and therapeutic combinations. Pharmaceuticals, 6(6):689-99.
15. Lipi LB, Begum N, Alam UK, Jahan R, Rahman MM and Rumana $R$. (2013): Study on role of magnesium Sulphate as a Tocolytic agent in preventing preterm labour. Journal of Dhaka Medical College, 22(2):179-84.

16. Lucovnik M, Kuon RJ, Chambliss LR, Maner WL, SHI SQ, Shi L, Balducci J and Garfield RE. (2011): Progestin treatment for the prevention of preterm birth. Acta Obstetricia et Gynecologica Scandinavica, 90(10):1057-69.

17. Meis PJ, Klebanoff M, Thom E, Dombrowski MP, Sibai B, Moawad AH, Spong CY, Hauth JC, Miodovnik M, Varner MW and Leveno KJ. (2016): Prevention of recurrent preterm delivery by 17 alphahydroxyprogesterone caproate. New England Journal of Medicine, 348 (24): 2379-85.

18. Nayeri UA, Buhimschi CS, Zhao G, Buhimschi IA and Bhandari V. (2018): Components of the antepartum, intrapartum, and postpartum exposome impact on distinct short-term adverse neonatal outcomes of premature infants: A prospective cohort study. PloS one, 13(12): e26111-e26111.

19. Norwitz ER and Caughey AB. (2011): Progesterone supplementation and the prevention of preterm birth. Reviews in Obstetrics and Gynecology, 4(2):60-72.

20. O'Brien JM, Adair CD, Lewis DF DeFranco EA, Hall DR, Fusey S, Soma-Pillay P, Porter $K$ and How $H$ (2012): Progesterone vaginal gel for the reduction of recurrent preterm birth: primary results from a randomized, double-blind, placebo-controlled trial. Ultrasound Obstet Gynecol, 30(5):68796.

21. Rebarber A, Istwan NB, RussoStieglitz K, Cleary-Goldman J, Rhea DJ, Stanziano GJ and Saltzman DH. 
(2014): Increased incidence of gestational diabetes in women receiving prophylactic 17alpha hydroxyprogesterone corporate for prevention of recurrent preterm delivery. Diabetes Care, 130(9):2277-80.

22. Tita AT, Landon MB, Spong CY, Lai Y, Leveno KJ, Varner MW, Moawad AH, Caritis SN, Meis PJ, Wapner RJ and Sorokin Y. (2015): Timing of elective repeat cesarean delivery at term and neonatal outcomes. New England Journal of Medicine, 8; 360(2):111-20.

23. Urquhart $\mathbf{C}$, Currell $\mathbf{R}$, Harlow $F$ and Callow L. (2017): Home uterine monitoring for detecting preterm labour. Cochrane Database of Systematic Reviews; Health Informatics Journal 16 (2): 3:1-11.
24. Vafaei H, Zamanpour $\mathbf{T}$ and Shahraki HR. (2016): Preterm birth prevention: effects of vaginal progesterone administration on blood flow impedance in uterine-fetal circulation by Doppler solography. Global Journal of Health Science, 8(7):172-175.

25. Wagner CK. (2016): Progesterone receptors and neural development: a gap between bench and bedside? Endocrinology, 149(6): 2743-9.

26. Xu FF, Sun S, Ho AS, Lee D, Kiang KM, Zhang XQ, Wang AM, Wu EX, Lui WM, Liu BY and Leung GK. (2014): Effects of progesterone vs. dexamethasone on brain oedema and inflammatory responses following experimental brain resection. Brain Injury, 28(12):1594-601. 


\section{دراسة مقارنة بين العلاج باستخدام محصرات قنوات الكالسيوم


رأفت محمد حسان، فريد إبراهيم حسن، مفيد فوزي محمد قسم أمراض النساءو و التوليد، كلية الطب، جامعة الأزهر

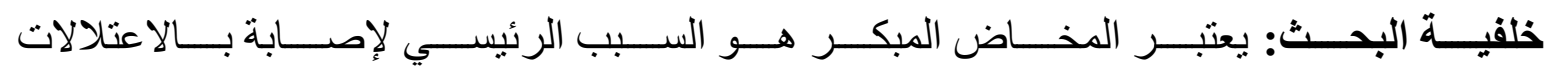

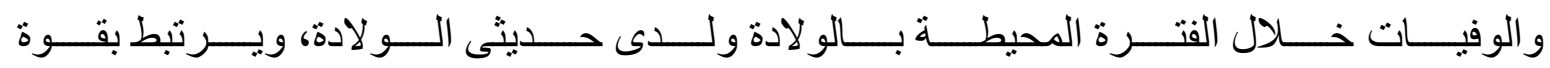
بالإعاقات النمائية و العصبية في وقت لاحق من الحياة.

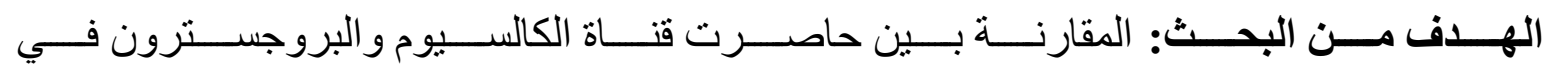

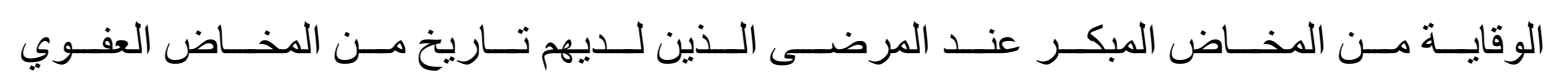
المتكرر.

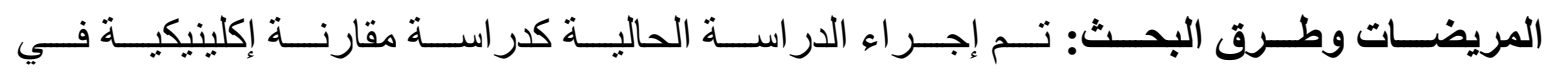

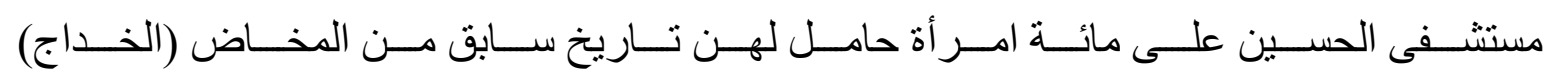

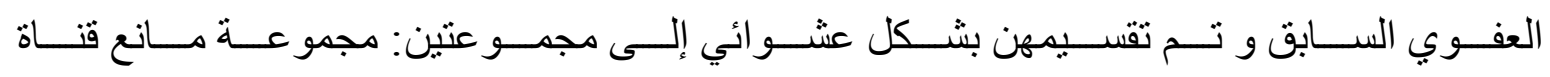
الكالسيوم)أ(ومجمو عة البروجسترون (ب).

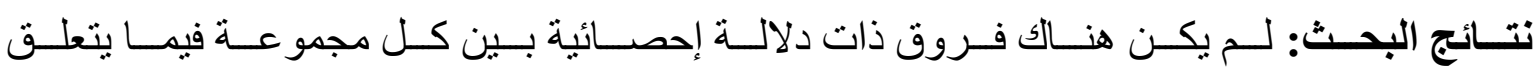

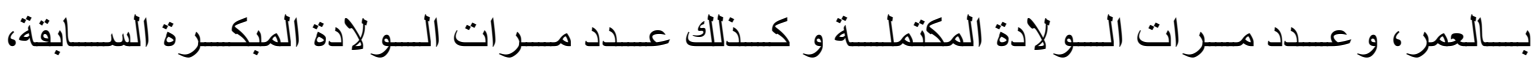

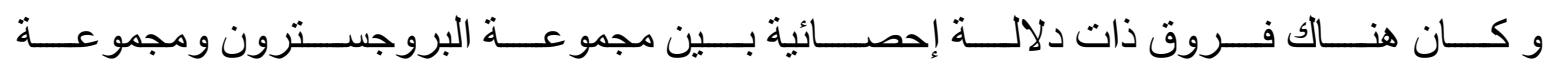

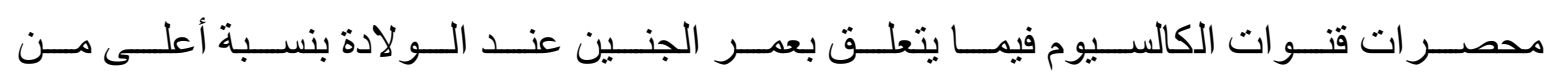

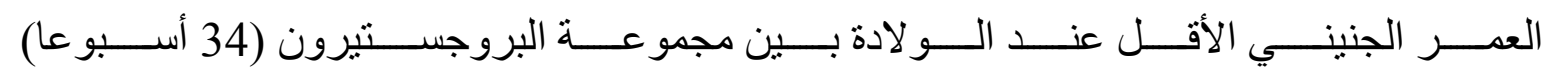

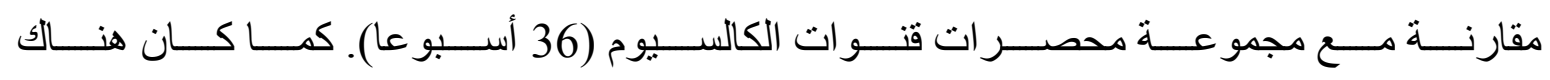

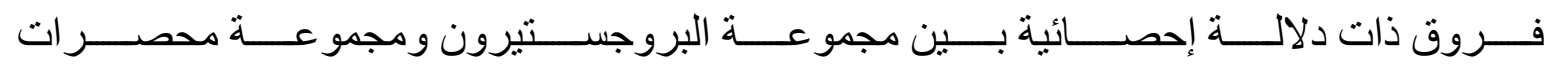

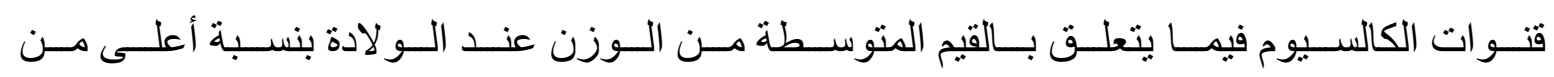

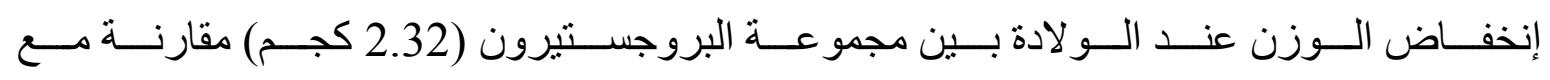

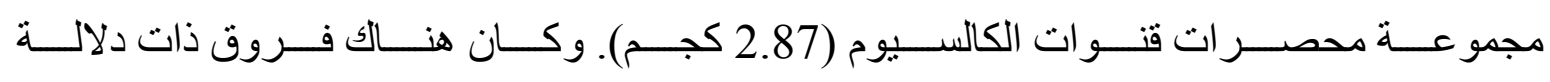

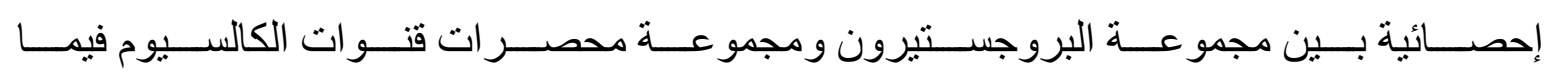

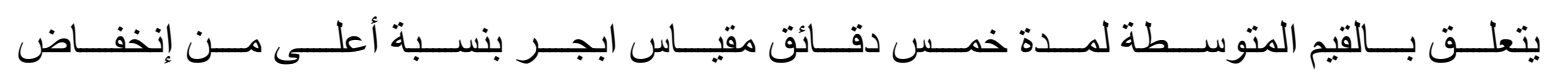




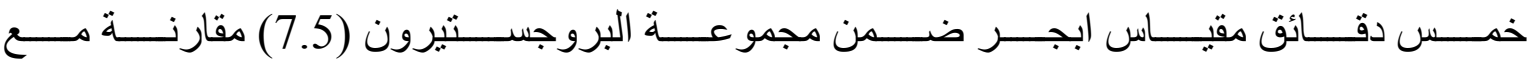

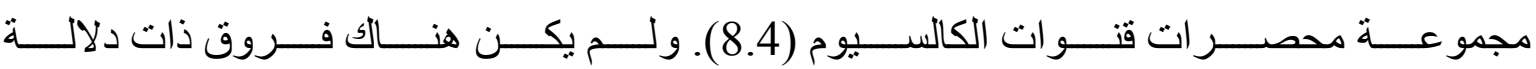
إحصائية بين المجمو عتين فيما بتعلق بطريقة الو لادة.

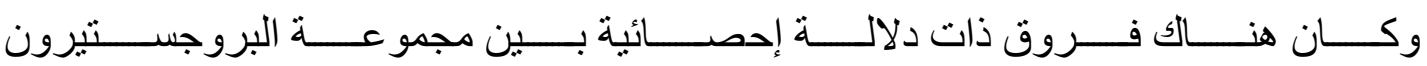

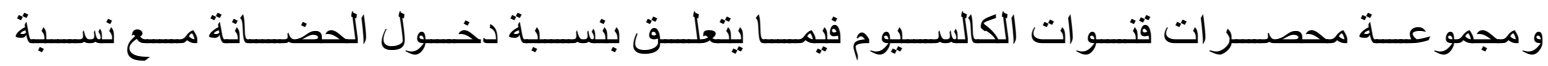

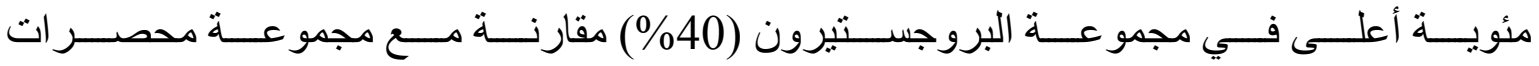
قنو ات الكالسيوم (11.4\%).

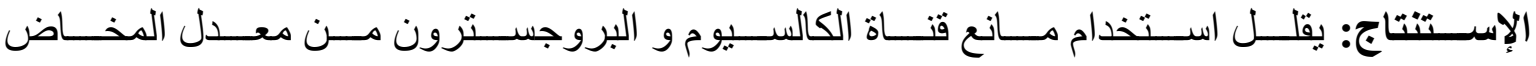

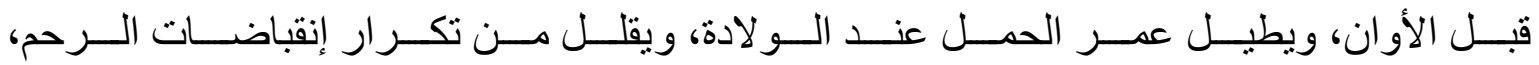

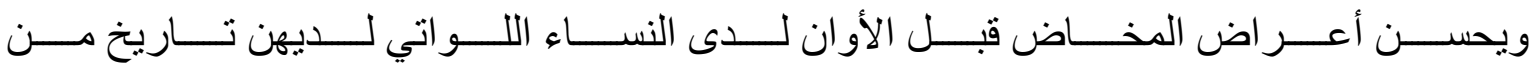

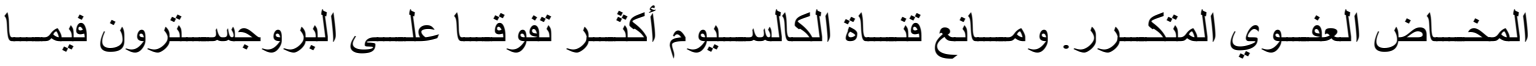
يتعلق بالوقاية من المخاض المتكرر. 